\title{
Two-phase CFD simulation of the monodyspersed suspension hydraulic behaviour in the tank apparatus from a circulatory pipe
}

\author{
${ }^{1}$ Roch Plewik, ${ }^{1,2}$ Piotr Synowiec, ${ }^{1}$ Janusz Wójcik \\ ${ }^{1}$ Silesian University of Technology, Department of Chemical Engineering, ul. ks. M. Strzody 7, 44-101 Gliwice, Poland \\ ${ }^{2}$ Institute of Inorganic Chemistry Gliwicach, e-mail: roch.plewik@polsl.pl
}

The hydrodynamics in fluidized-bed crystallizers is studied by CFD method. The simulations were performed by a commercial packet of computational fluid dynamics Fluent 6.x. For the one-phase modelling (15), a standard k- $\varepsilon$ model was applied. In the case of the two-phase flows the Eulerian multi-phase model with a standard k- $\varepsilon$ method, aided by the $\mathrm{k}-\varepsilon$ dispersed model for viscosity, has been used respectively. The collected data put a new light on the suspension flow behaviour in the annular zone of the fluidised bed crystallizer. From the presented here CFD simulations, it clearly issues that the real hydraulic conditions in the fluidised bed crystallizers are far from the ideal ones.

Keywords: CFD, fluidized-bed, crystallizers, tow phase flow.

\section{INTRODUCTION}

Fluidized-bed crystallizers have been used in industrial practice since $1925^{1}$. The devices are exploited mostly when large $(>1 \mathrm{~mm})$ crystals are desired. Although a lot of work was done on the subject, still more is needed to obtain a reliable model for design purposes. A new impact on the process has recently been made ${ }^{2-6}$. Most of previous works were based on the assumption of the ideal classifying bed e.g. ${ }^{7-12}$. Their disadvantage consisted in the fact that a monodisperse product was expected as a result. In reality the outcome is quite the opposite- the product is polydisperse.

Frances et al. ${ }^{3}$ utilised, on the contrary, an idea of a series of ideal mixers, one upon another as one multistage crystallizer, in order to take into account segregation and particles mixing within the bed. This model was compared to the experimental data of the laboratory-scale crystallization of tetrahydrate sodium perborate. It has given a good estimation of the mean product size and size distribution of crystals along the bed.

Only one model has used axial dispersion to describe fluidized-bed crystallizers ${ }^{13}$ which is the nearest to the real physical phenomenon. The authors have developed their model on the basis of Kennedy and Bretton ${ }^{14}$ and the well-known HTU notion. They have assumed that the fluidized-bed behaves as a perfect classified bed with one exception - there is a size distribution in every slice of the bed caused by axial dispersion. Their algorithm is very complicated, but as a result they obtained a polydisperse product, which was close to the experimental data of Shirotsuka et al. ${ }^{10}$.

This article presents the results of own modeling, applying the two-phase CFD method. So far only one attempt of modeling of the fluidized-bed crystallizer with this method has been found in accessible literature ${ }^{15}$ using one-phase models.

\section{MODELLING}

One of the most popular types of fluidized-bed crystallizers is the Oslo fluidized-bed crystallizer with a classification leg, which is presented in Fig.1. Crystals are fluidized by means of fresh solution circulation, going to the bed from a central tube and coming out by an overflow. The smallest crystals are elutriated from the bed by streams of solution. The largest crystals, whose sedimentation velocity is larger than that of the

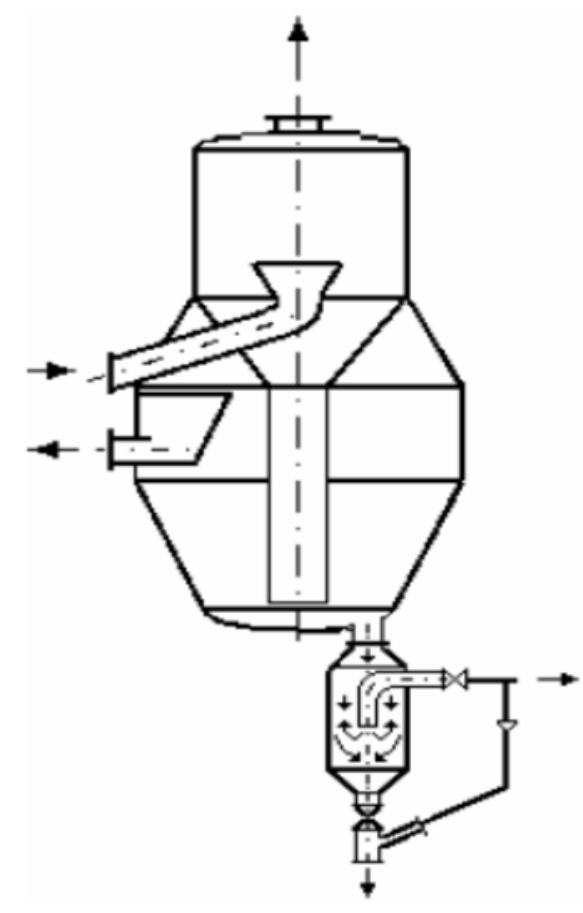

Figure 1. A scheme of the Oslo fluidized-bed crystallizer with the classification $\operatorname{leg}^{16}$

solution velocity, pass into the classification leg. The smaller crystals are removed from it by an additional inlet stream.

$\mathrm{In}^{17}$ there are some industrial data concerning $\mathrm{NaCl}$ crystallization, which were used for the preparation of a model. This report provides the information about the production of $3 \mathrm{t} / \mathrm{h}$ of $2-3 \mathrm{~mm} \mathrm{NaCl}$ (40 mass\% in suspension) crystals from $230 \mathrm{~m}^{3}$ apparatus of $6 \mathrm{~m}$ diameter. Simple calculations give equivalent porosity at the bottom of the classification leg equal to $\varepsilon=0.7328$. This value is required for the computation of crystals sedimentation velocity e.g. ${ }^{17}$. Using the modified formula of Todes

$\operatorname{Re}=\operatorname{Ar\varepsilon } \varepsilon^{5,75} /\left(18+0,6 \sqrt{A r \varepsilon^{4,75}}\right)$

proper conditions of the flow can be calculated. The working supersaturation level is read from ${ }^{18}$.

The book ${ }^{19}$ lists several articles concerning CFD simulation of crystallization processes. Unfortunately, none of these, nor others, found in accessible literature, deals with the fluidisedbed crystallizer. 
It has been decided to diminish the dimensions of the modelled crystallizer ten times in order to optimize the required computation time together with the accuracy of the model (Table 1).

Table 1. The main dimensions of the modelled crystallizer

\begin{tabular}{|c|c|c|}
\hline \multicolumn{2}{|l|}{ crystallizer diameter } & $0.600 \mathrm{~m}$ \\
\hline \multicolumn{2}{|l|}{ diameter of the central tube } & $0.100 \mathrm{~m}$ \\
\hline \multicolumn{2}{|l|}{ height } & $0.776 \mathrm{~m}$ \\
\hline \multirow{3}{*}{ height of the central tube outlet } & 1 & $0.041 \mathrm{~m}$ \\
\hline & 2 & $0.096 \mathrm{~m}$ \\
\hline & 3 & $0.141 \mathrm{~m}$ \\
\hline
\end{tabular}

Based on the above information a solution flux within the modelled crystallizer is calculated and the inlet solution velocity to the central tube can thus be estimated. For the simulations the following values were chosen: $0.0306,0.061,0.306,0.61$, $0.92,1.2 \mathrm{~m} / \mathrm{s}$.

The internal configuration of the apparatus can affect the performance of crystallization process considerably. Table 2 lists the internal configurations investigated.

Table 2. The internal configurations of the crystallizer under study

\begin{tabular}{|l|c|}
\hline Internal configuration & Symbol \\
\hline Conical end of the central tube & $\mathrm{A}$ \\
\hline Conical end of the central tube, stator & $\mathrm{B}$ \\
\hline Straight central tube & $\mathrm{C}$ \\
\hline Straight central tube, stator & $\mathrm{D}$ \\
\hline
\end{tabular}

The simulations were performed by a commercial packet of computational fluid dynamics Fluent 6.x, whose operation is based on the method of the finite volume. The unstructured three-dimensional mesh created in the Gambit programme for the whole volume of the crystallizer was applied to the calculations. The grid was created from mixed (tetrahedral/ hybrid) elements. The quality of the mesh was assessed using the EquiAngle Skew criterion. It was not permitted for the worst element of the grid to reach the value of $Q_{E S C}=0.82$.

a)

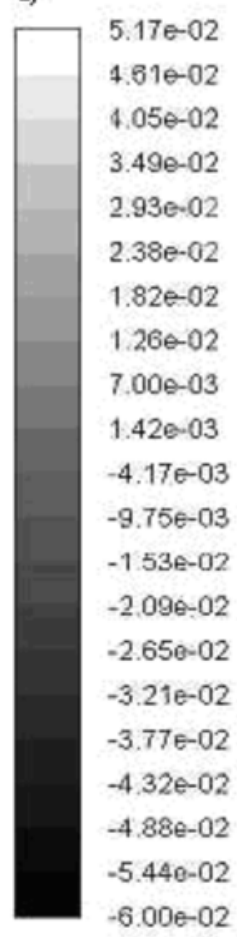

In every case the worst element was located. If its coordinates were in the crucial zone of the apparatus i.e. outside the central pipe, the mesh was adapted. Our model was tested for the grid from 20000 to 600000 computational cells. The grid used for the calculations consisted of 40,000 to 90,000 computational cells for the one-phase models and $37650 \mathrm{compu}-$ tational cells for the two-phase models.

For the one-phase (OP) modelling ${ }^{15}$ - when the flow is pure water - a standard k-e model was used for the simulations, fig.2, 3 and 4. In the case of the two-phase flows - when the flows are water with fluidized crystals, fig.: 5, 6, 7 and $8-$ the Eulerian multi-phase (MP) model with a standard k- $\varepsilon$ method, aided by the k- $\varepsilon$ (MP) dispersed model for viscosity, has been used respectively. To obtain the steady state and the convergence of $10^{-6}-10^{-8}$ of the normalized residuals, about 1000 to 2000 first order upwind iterations were required for the OP model ${ }^{15}$. To obtain the steady state and the convergence of $10^{-}$ ${ }^{4}-10^{-6}$ of the normalized residuals, about 1500 to 3000 first order upwind iterations were required for the MP model.

\section{RESULTS}

Axial liquor velocity is a very important parameter deciding about a proper operation of the crystallizer. Fig. 2 shows some exemplary results of this velocity profiles for two different apparatus configurations and inlet solution velocities. This velocity in the cross section A-A determines the minimal size of crystals hold - up in the bed. If it is larger than the sedimentation velocity of the crystals, they are being washed out from the bed. It is worth noting that instead of the theoretical horizontal zones of the same velocity in the conical part of the apparatus, as in case of the ideal crystallizer, one can observe the circulation loops.

It seems that a more flat velocity profile in the A-A crosssection (Fig. 2.b) will be an advantage for the crystallization process, allowing for more stable operation. It can be observed b)

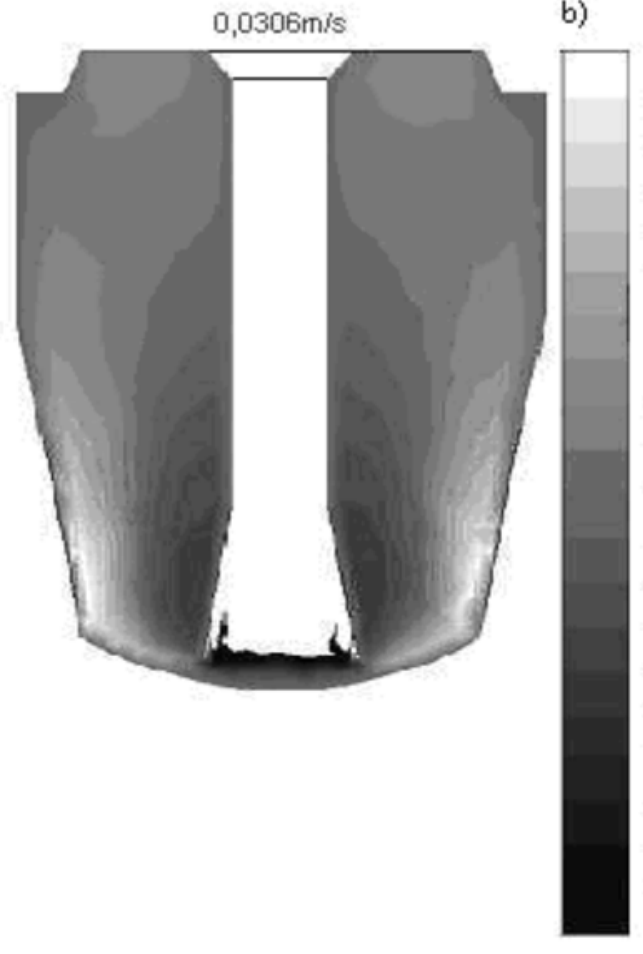

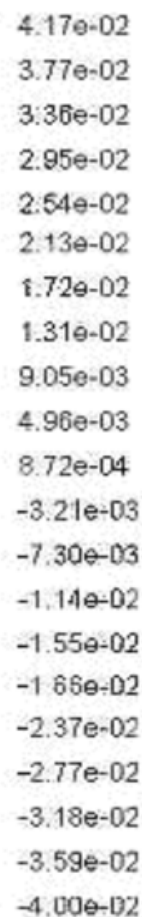

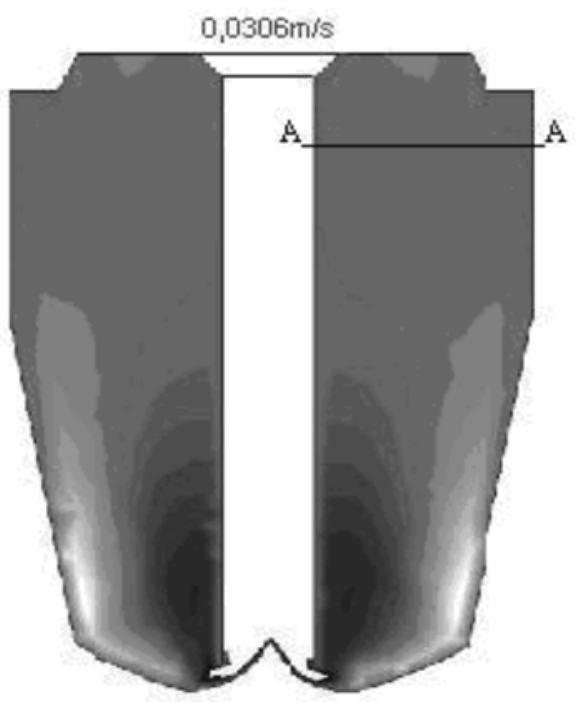

Figure 2. Comparison of the axial velocity profiles for different internal configurations and inlet velocities; note the A-A crosssection in part b) 
that the internal configuration and the position of the central tube outlet influence it considerably (Fig. 3 and 4.).

When analyzing the results, one can observe that for the inlet solution velocity equal to $0.306 \mathrm{~m} / \mathrm{s}$ and each internal configuration the maximum axial velocity in the A-A crosssection is smaller than the sedimentation velocity for the particles in the $0.0004 \div 0.0006 \mathrm{~m}$ range, when the porosity of the bed attains the upper limit of the so-called dense fluidized-bed $^{7}(\varepsilon=0.975)$. These crystals can be considered as the seed obtained from other stages of the $\mathrm{NaCl}$ factory (17). For the next inlet velocity $(0.61 \mathrm{~m} / \mathrm{s})$ only larger crystals $0.0007 \div 0.001 \mathrm{~m}$ will be held-up in the bed.

The maximal values of axial velocity in circulation loops (not listed here) provide proper conditions for growth in the fluidised-bed, even for quite large grains $(0.003 \mathrm{~m})$.

Some interesting facts obtained from this analysis are:

- Configuration 2B (the conical end of the central tube, stator, $h=0.096 \mathrm{~m}$ ) grants the smallest values of the maximum axial velocity in the A-A cross-section for all apart from two the lowest inlet velocities. So it is the hydrodynamically optimal internal configuration.

- Configuration 1A (the conical end without the stator, $h$ $=0.041 \mathrm{~m}$ ) provides the highest values of the maximal axial velocity in the A-A cross-section also for all except for two smallest inlet velocities.

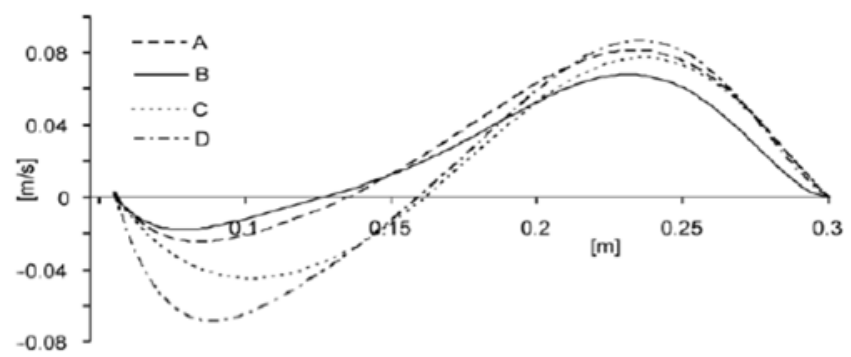

Figure 3. Comparison of solution velocity profiles in the AA cross-section for different internal crystallizer configurations (the second position of the central tube, the inlet solution velocity $0.61 \mathrm{~m} / \mathrm{s}$; the outer wall of the central tube corresponds to $\mathrm{x}=0.06 \mathrm{~m}$ )

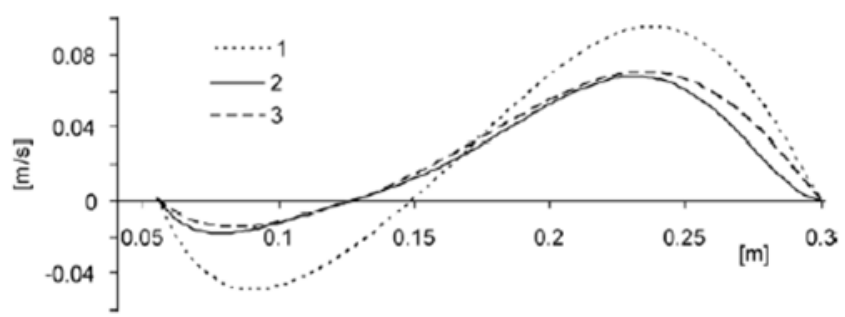

Figure 4. The influence of the outlet position of the central tube on the velocity profile in the A-A cross-section for the conical tube with the stator (the outer wall of the central tube corresponds to $\mathrm{x}=0.06 \mathrm{~m}$ )

In figure 5, the results of the calculations focused on the volumetric concentration distribution of the monodispersed sand particles in the fluidised bed are presented. The shape of the vessel was similar to that, which is used in industrial fluidised bed crystallizers. The computations, for constant the value of liquid velocity in the central pipe have been carried out. Four sizes of particles, i.e. 1, 2, 3, $4 \mathrm{~mm}$ were employed, respectively.

The results confirm the earlier observations from literature ${ }^{20}$, concerning the strong heterogeneous particles concentration distributions in both the horizontal as well as in the vertical cross section of the apparatus. The character of the liquid flow proves the existence of inner circulation loops in both mentioned directions, (Fig. 6, 7 and 8). These inner circulation loops undoubtedly affect the heterogeneous behaviour of the bed. The form of the apparatus shell necessary for the hydraulic classification of polidyspersed suspension in industrial conditions, as well as the conical outlet from the central pipe, aid disadvantageous axial velocity distribution in the annular zone of a vessel, Fig 6 and 7. The vortex liquid flow, Fig. 8, additionally generates energy dissipation, which increases crystals destruction and the erosion of the inner jacket surface.

In the investigated examples, the most homogeneous suspension has been obtained, when the mean bed porosity was in the range of $0.70-0.85$. As a consequence of the nonuniform velocity distribution, the highest concentrations of the particles have been situated on the outside of the central pipe conical outlet and in the upper part of the bed near the apparatus's inner surface, respectively.

A comparison of the mean liquid velocity in the annular zone with the mean velocity of fluidisation, as the $\mathrm{w}_{\mathrm{m}} / \mathrm{w}_{\mathrm{fl}}$ ratio clearly shows the narrow range of $0.90-1.15$ values, in which the volumetric concentration distribution was satisfying. It proves a significant importance of accuracy in fluidisation velocity determination for each particles range and local porosity.

\section{SUMMARY}

Selection is performed of proper internal configuration and inlet velocity to get the optimal hydrodynamic operating conditions for the process in the fluidized-bed crystallizer. A scheme of the Oslo fluidized-bed crystallizer with the classification leg $^{16}$ is presented in Fig. 1. From article ${ }^{17}$ the industrial data concerning $\mathrm{NaCl}$ crystallization were read and used for the preparation of the model. Table 1 presents the main dimensions and Table 2 the internal configurations of the investigated crystallizer. Simulations were performed by the Fluent 6.x. A standard k- $\varepsilon$ one-phase model was used. Some exemplary results are presented in this article. Fig. 2 shows a comparison of the axial velocity profiles for different internal configurations and inlet velocities; Fig. 3 - the comparison of solution velocity profiles in the A-A cross-section for different internal crystallizer configurations (the second position of the central tube, the inlet solution velocity $0.61 \mathrm{~m} / \mathrm{s}$ ); Fig. 4 - the influence of the central tube outlet position on the velocity profile in the A-A cross-section for the conical tube with the stator; Configuration 2B (the conical end of the central tube, stator, $h=0.096 \mathrm{~m}$ ) gives the smallest values for the maximum axial velocity in the A-A cross-section for all, besides two smallest inlet velocities.

The one-phase CFD model is not quite appropriate for the fluidised-bed crystallization because the influence of the dispersed phase is omitted there ${ }^{\mathbf{2 1}}$. However, it is good enough for the first screening, especially for the areas where the suspension concentration is low (like in the A-A cross-section).

The developed method of the two-phase flow is a useful tool for the analysis of the fluidised bed in the apparatus. For the two-phase flow, the Eulerian multiphase (MP) model with the standard k- $\varepsilon$ method aided by k- $\varepsilon$ (MP) dispersed model for viscosity has been used respectively.

The collected data put a new light on the suspension flow behaviour in the annular zone of the fluidised bed crystallizer. 
a)

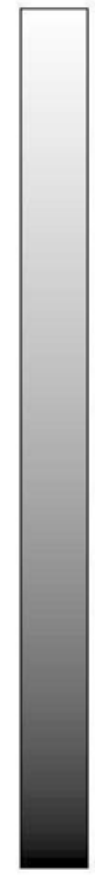

b)

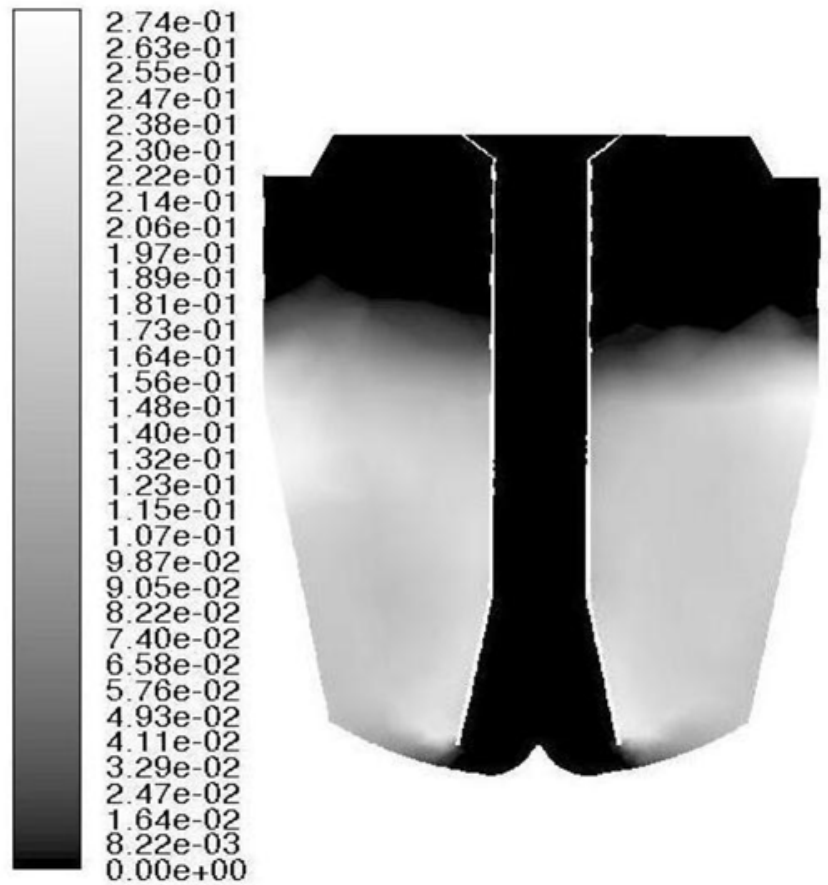

d)

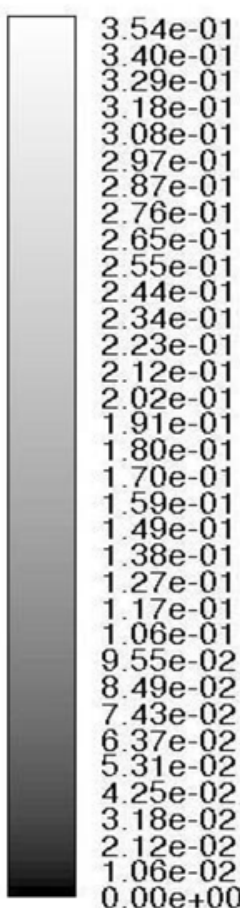

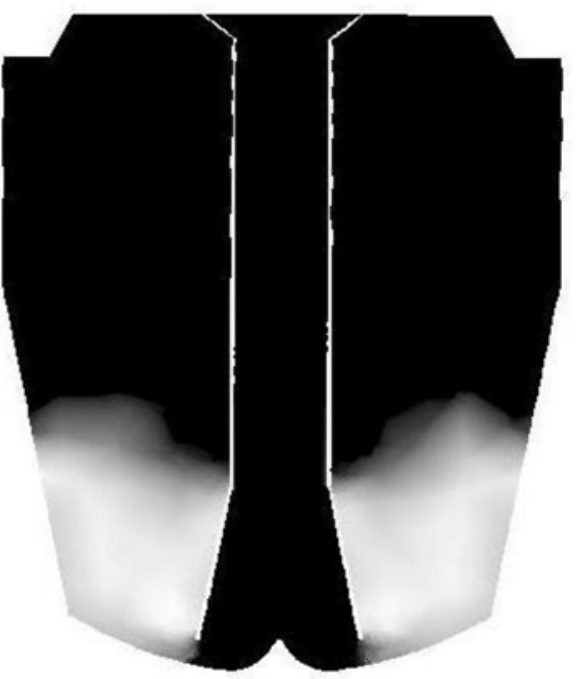

c)

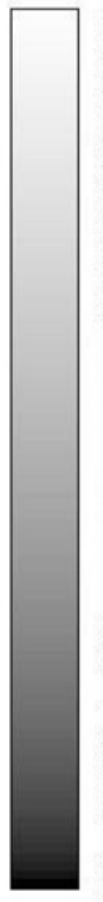

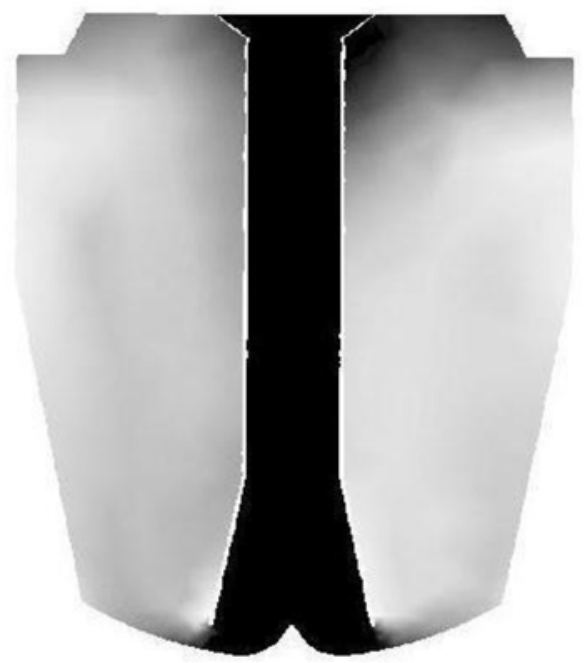

2. $41 \mathrm{e}-03$

$1.21 \mathrm{e}-03$

$0.00 \mathrm{e}+00$
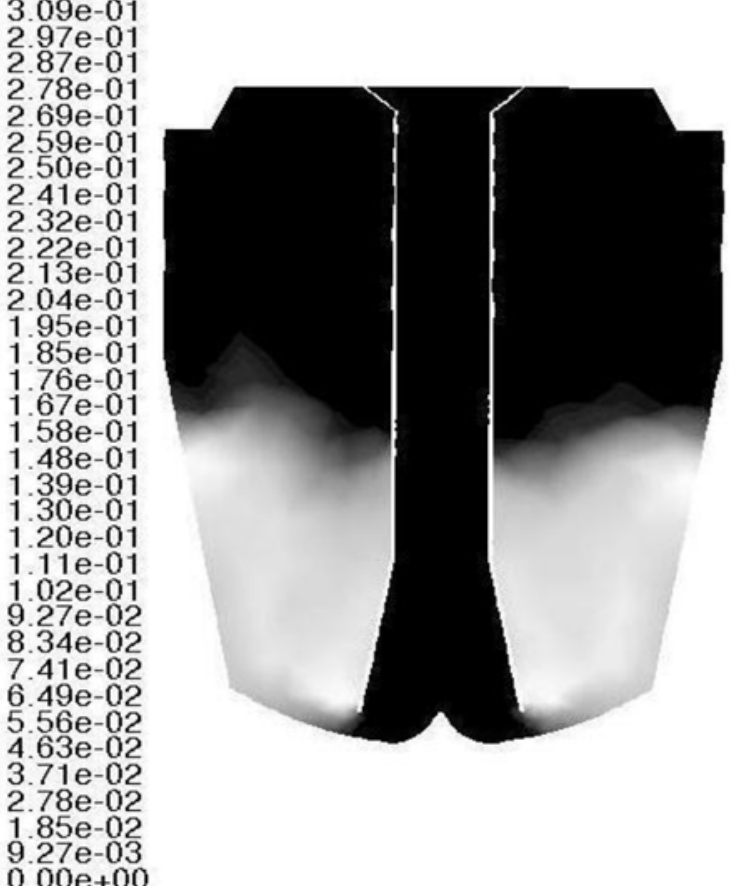

Figure 5. The influence of size of crystallites on the deposit of the fluidal-bed crystallizer for $\varphi=10$; a) $1=1 \mathrm{~mm}$; b) $1=2 \mathrm{~mm}$; c) $1=3 \mathrm{~mm}$; d) $1=4 \mathrm{~mm}$

From the presented here CFD simulations, it clearly issues that the real hydraulic conditions in the fluidised bed crystallizers are far from the ideal ones. The existing inner circulation loops prevent a more uniform particle concentration distribution. The vortex flow of the liquid increases energy dissipation and crystal attrition, as well. Thus the next step focused on the optimisation of the crystallizer's shape should be done in order to get a more homogeneous particle concentration distribution and to reduce the vortex flow of the suspension.

\section{SYMBOLS}

A

$R e$

$h$

1

$\mathrm{w}_{\mathrm{m}}$

$\mathrm{W}_{\mathrm{fl}}$

$Q_{E S C}$

$A r$
- Archimedes number

- height of the central

central tube outlet $\mathrm{m}$

- diameter of crystallites

- velocity solution

- velocity fluidization

- coefficient of EquiAngle Skew

- dimensionless distance from the wall

- porosity of the bed

- volumetric concentration 


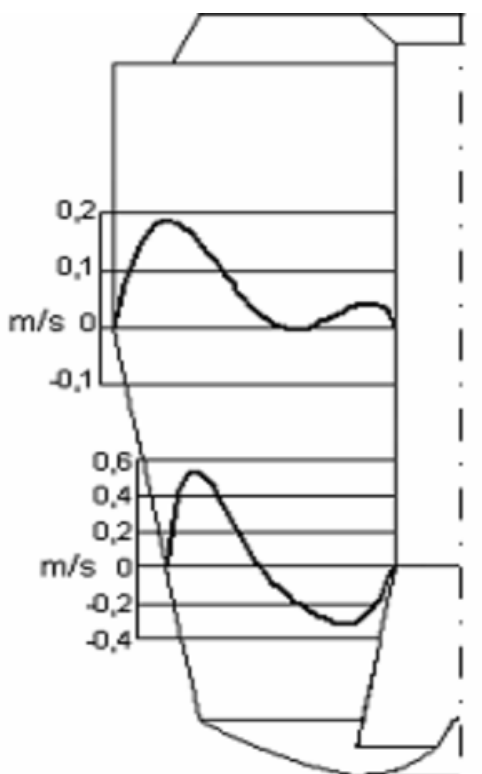

Figure 6. Profiles of axial speeds in the transverse section of the apparatus for $\varphi=10 \% ; 1=2 \mathrm{~mm}$

a)

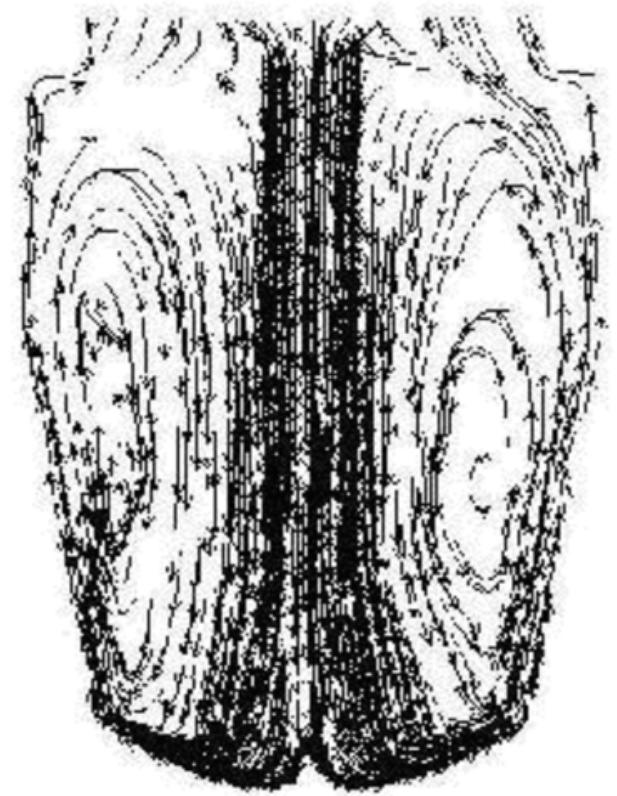

c)

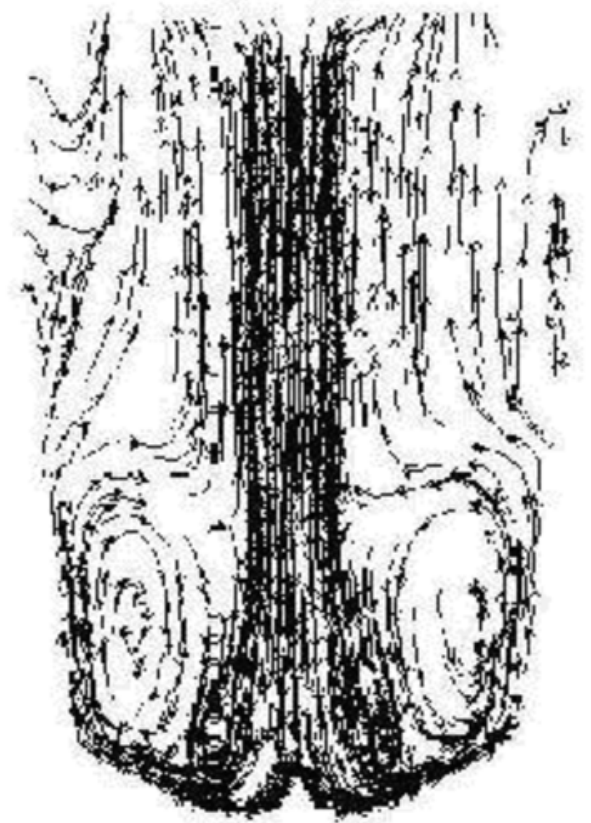

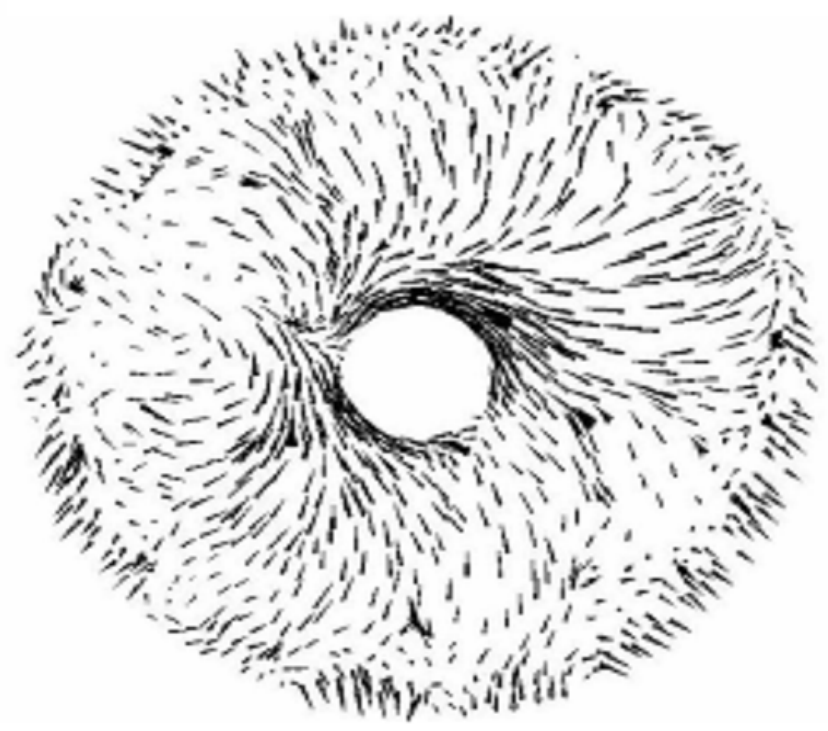

Figure 7. Radial speed in the annular section of the apparatus for $\varphi=10 \% ; 1=2 \mathrm{~mm}$

b)

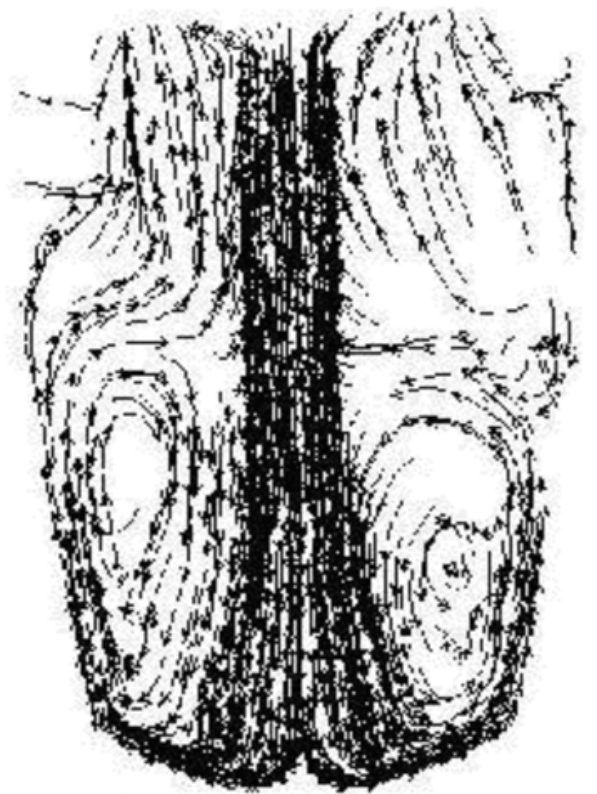

d)

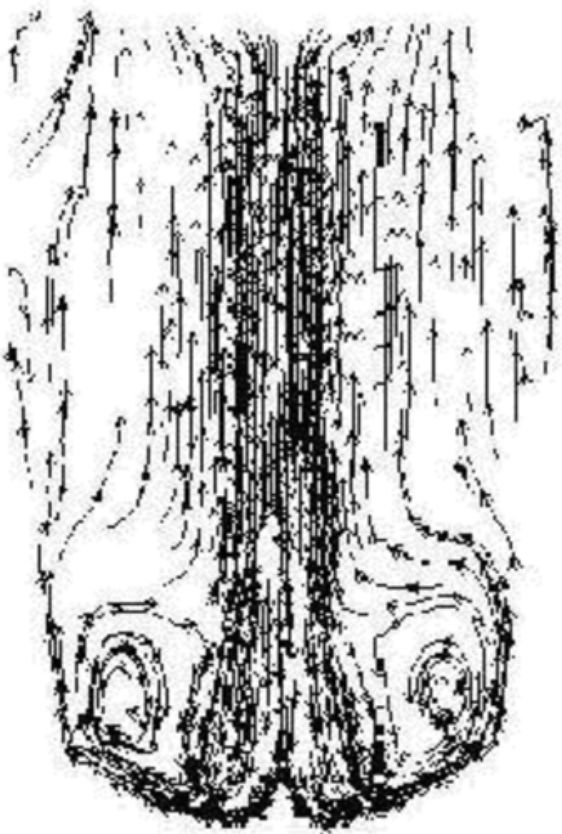

Figure 8. The schedule of the internal circulations of suspension for $\varphi=10$; a) $1=1 \mathrm{~mm}$; b) $1=2 \mathrm{~mm}$; c) $1=3 \mathrm{~mm}$; d) $1=$ $4 \mathrm{~mm}$ 


\section{LITERATURE CITED}

1. Isaachsen, I. \& Jeremiassen, F.(1925). Ein neues industrielles Kristallisierungs-verfahren, Zeitsch. Ang. Chem., $38,317-322$.

2. Ulrich, J. \& Stepanski, M. (1987). Einfluß der Oberflächen-Beschaffenheit auf das Kristallwachstum aus Lösungen, Chem.-Ing.-Tech., 59, 5, 402 - 404.

3. Frances, C., Biscans, B. \& Laguerie, C. (1994). Modelling of a continuous fluidized-bed crystallizer Effect of mixing and segregation on crystal size distribution during the crystallization of tetrahydrate sodium perborate, Chem. Engng Sci. 49, 3269 - 3276.

4. Mohameed, H. A. \& Ulrich, J. (1996). Influence of the $\mathrm{pH}$-Value on the growth and dissolution rate of potassium chloride, Cryst. Res. Technol., 31, 1, 27 - 31.

5. Belcu, M. \& Turtoi, D. (1996). Simulation of the fluidized-bed crystallizers (I) Influence of parameters, Cryst.Res.Technol., 31, 8, 1015 - 1023.

6. Omar, W. \& Ulrich, J. (1997). Influence of the $\mathrm{Fe}^{+2}$ ions on the dissolution rate of potassium chloride, Cryst.Res.Technol., 32, 6, 789 - 797.

7. Pulley, C.A. (1962). The Krystal crystallizer, The Ind. Chem., 38, 63 - 66, 127 - 132, 175 - 178.

8. Matz, G. (1964). Untersuchungsmethoden für die klassifizierende Krystallisation, Wärme, 70, 3, 99 - 107.

9. Bransom, S.H. (1965). Continuous crystallizer design, Chem.Proc.Eng., 46, 12, 647 - 653.

10. Shirotsuka, T., Toyokura, K. \& Sekiya, Y. (1965). Method for calculating the height of the continuous clasifiedbed type crystallizer, Kagaku Kogaku, 29, 698 - 704,.

11. Mullin, J.W. \& Nývlt, J. (1970). Design of classifying crystallizers, Trans. Instn Chem. Engrs, 48, T7 - T14.

12. Wójcik, J. (1997). Population balance in a fluidizedbed crystallizer with ideal classification, Inż. Chem. Proc., 18, 3, 411 - 426 (in Polish).

13. Toyokura, K., Tanaka, H. \& Tanahashi, J. (1973). Size distribution of crystals from classified bed type crystallizer, J. Chem. Eng. Jap., 6, 4, 325 - 331.

14. Kennedy, S.C. \& Bretton, R.H. (1966). Axial dispersion of spheras fluidized with liquids, AIChEJ, 12, 1, $24-32$.

15. Wójcik, J. \& Plewik, R. (2007). CFD modelling of a fluidized-bed crystallizer, Inż Chem. Proc. 28, 75 - 83.

16. Synowiec, P. , Kwiecień, J. \& Tomanek, G. (2003). Opracowanie metody obliczeniowej odnogi klasyfikującej w krystalizatorach przemysłowych, IChN report 4268, Gliwice.

17. Messing, T. \& Hofmann, G. (1980). Industrielle Kristallisation - Moderne grobtechnische Anlagen und Fallstudien, Chem.-Ing.-Tech. 52, 11, $870-874$.

18. Rumford, F. \& Bain, J. (1960). The controlled crystallization of sodium chloride, Trans. Instn. Chem. Engrs, 38, $10-20$.

19. Jaworski, Z. (2005). Numeryczna mechanika płynów w inżynierii chemicznej i procesowej, A.O.W. EXIT, Warszawa.

20. Sha, Z. \& Palosaari, S. (2000). Mixing and crystallization in suspensions Chem. Eng. Sci., 55, 1797 - 1806.

21. Bałdyga, J. (2001). Zastosowanie obliczeniowej mechaniki płynów (CFD) w inżynierii chemicznej i procesowej, Inż. Chem. Proc., 22, 3A, 3 - 14. 